\title{
EXPERIÊNCIA DE PROJETO DE INSTALAÇÕES HIDROSSANITÁRIAS EM BIM DURANTE O ENSINO NÃO PRESENCIAL
}

\section{A BIM plumbing systems design experience during emergency remote teaching}

\begin{abstract}
LEEPKALN, Carlos Eduardo; ROSA, Inaê Silva²; BRANDÃO, Milena de Mesquita ${ }^{3}$
Recebido em 16 de julho de 2021, aprovado em 06 de setembro de 2021, publicado em 18 de novembro de 2021

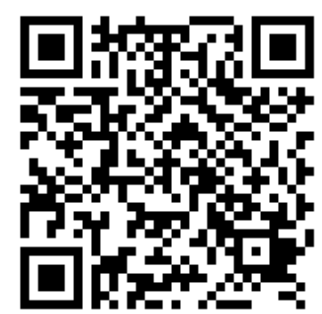

Palavras-chave:

Instalações

Hidrossanitárias;

BIM;

Ensino remoto.

Keywords:

Plumbing systems;

BIM;

Emergency remote teaching.

RESUMO: A partir de janeiro de 2021, a utilização do Building Information Model (BIM) em obras e serviços de engenharia da esfera pública federal tornouse obrigatória. No entanto, os cursos de graduação em Engenharia Civil abordam de maneira superficial essa metodologia, reduzindo-a muitas vezes a uma forma de representação gráfica, simplesmente. Sendo assim, o objetivo deste artigo é relatar uma experiência de projeto hidrossanitário para edifícios residenciais multifamiliares desenvolvido em uma unidade curricular não presencial em um curso de graduação de Engenharia Civil. Testou-se a utilização do método BIM na realização de um projeto hidrossanitário predial e constatou-se que apesar do ensino ser remoto, a realização do projeto foi eficiente, rápida e dinâmica.

ABSTRACT: From January 2021, using Building Information Model (BIM) in engineering works and services in the federal public system became mandatory. However, undergraduate courses in Civil Engineering superficially approach this methodology, often reducing it to a form of graphical representation. Therefore, the aim of this article is to report an experience of a Plumbing systems project for residential buildings developed during the emergency remote teaching in an undergraduate course in Civil Engineering. The use of the BIM method was tested in the realization of a building plumbing project and it was found that despite the teaching being remote, the project was efficient, fast and dynamic.
\end{abstract}

\section{CONTATO DOS AUTORES:}

${ }^{1}$ LEEPKALN, Carlos Eduardo: Graduando em Engenharia Civil, Instituto Federal de Educação, Ciência e Tecnologia de Santa Catarina, carlos.I10@aluno.ifsc.edu.br.

${ }^{2}$ ROSA, Inaê Silva: Graduanda em Engenharia Civil, Instituto Federal de Educação, Ciência e Tecnologia de Santa Catarina, inae.sr@aluno.ifsc.edu.br.

${ }^{3}$ BRANDÃO, Milena de Mesquita: Arquiteta e Urbanista, Mestre, Instituto Federal de Educação, Ciência e Tecnologia de Santa Catarina, milena.brandao@ifsc.edu.br. 


\section{INTRODUÇÃO}

O Decreto Federal no 10.306 (BRASIL, 2020) implementa nas obras e serviços de engenharia, realizada pelos órgãos e pelas entidades da administração pública federal a utilização Building Information Model (BIM) a partir de 01 de janeiro de 2021, de modo gradual. O BIM vem se mostrando como tendência desde o início dos anos 2000, ao redor de todo mundo, por proporcionar redução de custos, maior controle nos processos e aumento da produtividade nos projetos. Considerando este contexto, os cursos de graduação precisam se atualizar trazendo a lógica BIM nas unidades curriculares.

O Curso de Graduação em Engenharia Civil do IFSC - Câmpus Florianópolis, em seu projeto pedagógico de curso (IFSC, 2013), que está vigente desde 2014, não apresenta em seu texto a metodologia BIM. No entanto, na unidade curricular de Desenho Auxiliado por Computador os estudantes modelam em 3D um projeto arquitetônico no software REVIT. A carga horária semestral de 40 horas/aula permite com que os estudantes aprendam somente de forma introdutória a utilização do software.

Nas unidades curriculares de projetos complementares, como estruturas de concreto, aço e madeira; instalações elétricas e hidrossanitárias, projeto preventivo contra incêndio e sistemas de climatização, não existe obrigatoriedade em utilizar BIM. Sendo assim, muitos estudantes optam por desenvolver projetos em AutoCAD, por julgarem ser menos trabalhoso para cumprir o objetivo e os prazos das disciplinas. Além disso, cabe destacar que os computadores existentes nos laboratórios didáticos da instituição, em sua maioria, estão desatualizados e não apresentam desempenho satisfatório em modelagens mais complexas.

No semestre letivo de 2020.2, ministrado de forma não presencial devido à pandemia da COVID-19, na Unidade Curricular Instalações Hidrossanitárias do sexto semestre do curso, com carga horária semestral de 80 horas/aula, apenas três, de um total de 32 estudantes, divididos em duas turmas, se voluntariam para desenvolver seus projetos em BIM, o baixo percentual é ilustrado na Figura 1.

Figura 1 - Comparativo entre o desenvolvimento de projetos em AutoCad e REVIT

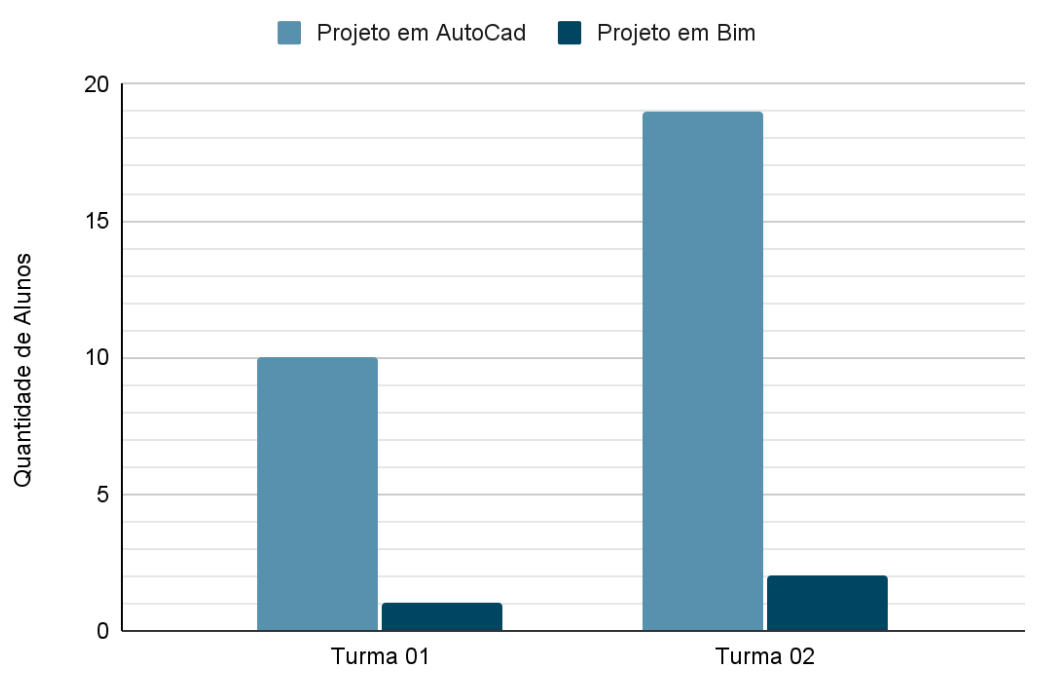

Fonte: autores (2021). 
Considerando o contexto apresentado, o objetivo deste artigo é relatar uma experiência de desenvolvimento de projeto hidrossanitário para edifícios residenciais multifamiliares em uma unidade curricular ministrada de modo não presencial em um curso de graduação de Engenharia Civil.

\section{PROJETOS DESENVOLVIDOS EM CAD 2D X PROJETOS DESENVOLVIDOS ADOTANDO A METODOLOGIA BIM}

O Desenho Auxiliado por Computador, do inglês Computer Aided Design (CAD), permite a geração de desenhos plotados em duas dimensões (2D) e modelagem em três dimensões (3D). Esses desenhos são compostos basicamente por vetores em diferentes camadas (layers), permitindo também a criação de blocos de dados e textos associados (CHUCK et al 2014, p.12)

A Modelagem da Informação da Construção, do inglês Building Information Modeling (BIM), permite a criação de um modelo virtual de uma edificação com precisão. Esse modelo virtual, quando alimentado de todas as informações da construção, possui a forma exata e todos os dados necessários para a sua execução real (CHUCK et al 2014, p.1). Assim, é possível reduzir os erros na obra e agilizar a execução, uma vez que o projeto arquitetônico e complementares estão compatibilizados neste modelo virtual.

Pode-se dizer que o CAD permite realizar desenhos em 2D e 3D por meio de um software, facilitando a representação gráfica de um projeto. Já o BIM permite construir um projeto virtualmente, considerando de forma unificada e compatibilizada o projeto arquitetônico e complementares, possibilitando a extração de diversas informações. Neste sentido, cabe considerar o BIM como uma metodologia projetual que extrapola a simples representação gráfica em 2D e 3D de diferentes projetos. Kensek (2018, p.7) afirma que o BIM não se resume a um desenho em três dimensões, mas é um banco de dados integrado e estruturado de todos os componentes da construção.

Uma das principais características das ferramentas BIM é a vinculação, que permite ter um olhar de futuras incompatibilidades, detectando conflitos entre projeto arquitetônico e complementares. No AutoCAD, a compatibilização é feita de maneira mais lenta e manual. A modelagem 3D proporcionada pelo BIM traz dinamismo e clareza ao processo de compatibilização.

Outra vantagem da metodologia BIM é a possibilidade da modelagem paramétrica. Essa função é capaz de adicionar pré-configurações a um modelo, como por exemplo nos hidrossanitários, as quais são pré-definidas as conexões, os diâmetros e inclinações, tornando o ato de projetar mais rápido e dinâmico. Por outro lado, os softwares de ferramentas 2D, não permitem essas alterações, uma vez que o projeto é composto por um conjunto de vetores e não como elementos com informações.

Entende-se que, para o uso das ferramentas BIM, no cotidiano dos cursos de graduação e nos escritórios de engenharia, é necessária formação específica sobre a metodologia e sua aplicação $O$ investimento em horas de estudo e computadores com maior desempenho pode ser elevado. Além disso, muitos optam por continuar trabalhando com base no método antigo, no qual cada projetista faz seu trabalho isoladamente e direciona para execução, ficando a cargo do engenheiro de execução solucionar conflitos dos projetos.

Em outra frente, por não haver muitos profissionais envolvidos com o conceito BIM, a quantidade de materiais disponíveis gratuitamente é escassa. Dessa forma, é preciso 
desenvolver as famílias paramétricas para elaboração dos projetos, o que requer horas de estudo e desenvolvimento.

\section{RELATO DE EXPERIÊNCIA DE DESENVOLVIMENTO DE PROJETO DE INSTALAÇÕES HIDROSSANITÁRIAS EM UNIDADE CURRICULAR DE GRADUAÇÃO}

A graduação em Engenharia Civil do IFSC - Câmpus Florianópolis, cujo Projeto Pedagógico de Curso está vigente desde 2014 (IFSC, 2013), aborda a utilização do software REVIT em uma disciplina de Desenho Auxiliado por Computador, do terceiro semestre. Apesar de não haver tempo hábil para aprofundar os conhecimentos sobre a metodologia BIM na unidade curricular, alguns estudantes acabam sendo instigados a se aprofundar na utilização da ferramenta, aplicando-a no desenvolvimento de diferentes projetos ao longo do curso e buscando estágios em escritórios que adotam o BIM.

Em Instalações Hidrossanitárias, do sexto semestre do curso, busca-se desenvolver a competência de projetar as instalações prediais de água fria, quente, esgoto sanitário e águas pluviais de edificações comerciais e residenciais (IFSC, 2013). Como exercício acadêmico, os estudantes desenvolvem individualmente projeto hidrossanitário de um edifício residencial multifamiliar com quatro pavimentos-tipo e dois de serviços gerais, projetado por eles na unidade curricular de Projeto Arquitetônico. A maioria dos estudantes realiza esta atividade acadêmica utilizando AutoCAD, uma vez que os professores não costumam abordar a metodologia BIM para os projetos complementares.

Um dos pilares do curso é desenvolver as habilidades dos acadêmicos por meio do desenvolvimento detalhado de projetos ao longo dos semestres letivos. Dessa forma, os estudantes são estimulados a buscar por soluções de problemas dos projetos complementares desde do início do projeto arquitetônico.

Durante o isolamento imposto pela pandemia da COVID-19, os conteúdos passaram a ser ministrados remotamente. Acredita-se que essa possibilidade de estudar por meio de vídeos, com conteúdos não somente elaborados pelos docentes das unidades curriculares, mas também por outros cursos disponíveis online, fez com que os estudantes buscassem outras formas de desenvolver o seu projeto. Após realizar curso online gratuito de $6 \mathrm{~h}$, disponível na Plataforma Cursos Construir ${ }^{1}$, alguns estudantes decidiram pela metodologia BIM na unidade curricular de Instalações Hidrossanitárias. Para realização desses projetos em BIM, os estudantes precisavam acessar a extensão MEP (mechanical, electrical, and plumbing-piping) do REVIT, plugin necessário para projetos mecânicos (M), elétricos (E) e de instalações hidrossanitárias $(\mathrm{P})$.

As Figuras 2 e 3 comparam o detalhamento das instalações de esgoto de um banheiro de um edifício residencial multifamiliar. É disponibilizado aos estudantes um arquivo de AutoCAD com blocos de todas as conexões em três diferentes vistas. Por estarem tendo um primeiro contato com o conteúdo, os estudantes demonstram dificuldade em entender as conexões e como encaixá-las. Outra dificuldade é visualizar essas instalações, principalmente com relação à localização dos ramais (abaixo da laje) e de seus encaixes com tubo de queda e coluna de ventilação. Consequentemente, é possível determinar, por exemplo, precisamente a altura do forro. Essa dificuldade de visualização no AutoCAD fica evidente pela quantidade de atividades com erros entregues pelos estudantes. Ao ir "construindo" a instalação em meio virtual, 
tendem a aplicar as diretrizes de projeto previstas pelas normas de maneira bastante eficiente, minimizando erros de projeto. Os estudantes, ao navegarem nesta "construção virtual" demonstram uma familiaridade com o projeto muito maior do que aqueles que 0 desenvolveram utilizando o AutoCAD.

Figura 2 - Desenho técnico de um banheiro - Software AutoCAD

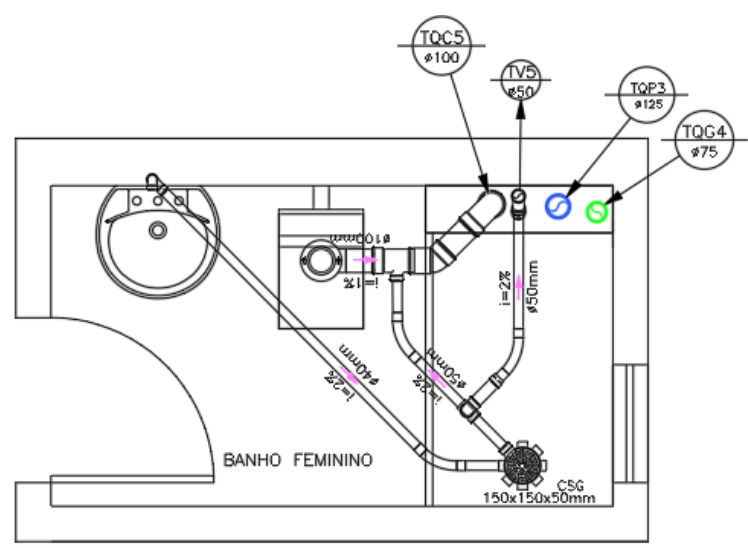

Fonte: autores (2021).

Figura 3 - Modelagem de um banheiro - Software REVIT MEP

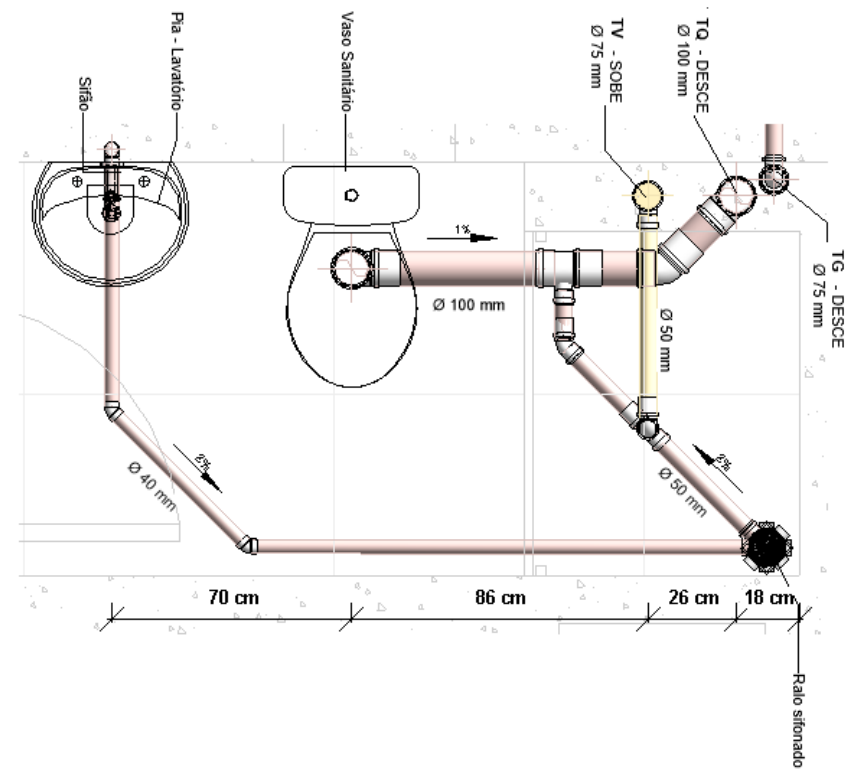

Fonte: autores (2021).

Os estudantes autores deste artigo realizaram modelagem completa no REVIT MEP. Verificouse que esse software dinamiza troca de informação entre modelagem arquitetônica e hidrossanitária, possibilitando soluções rápidas e precisas, como a melhor localização dos shafts, ilustrado na Figura 4. 


\section{Figura 4 - Modelagem Predial - Software REVIT MEP}

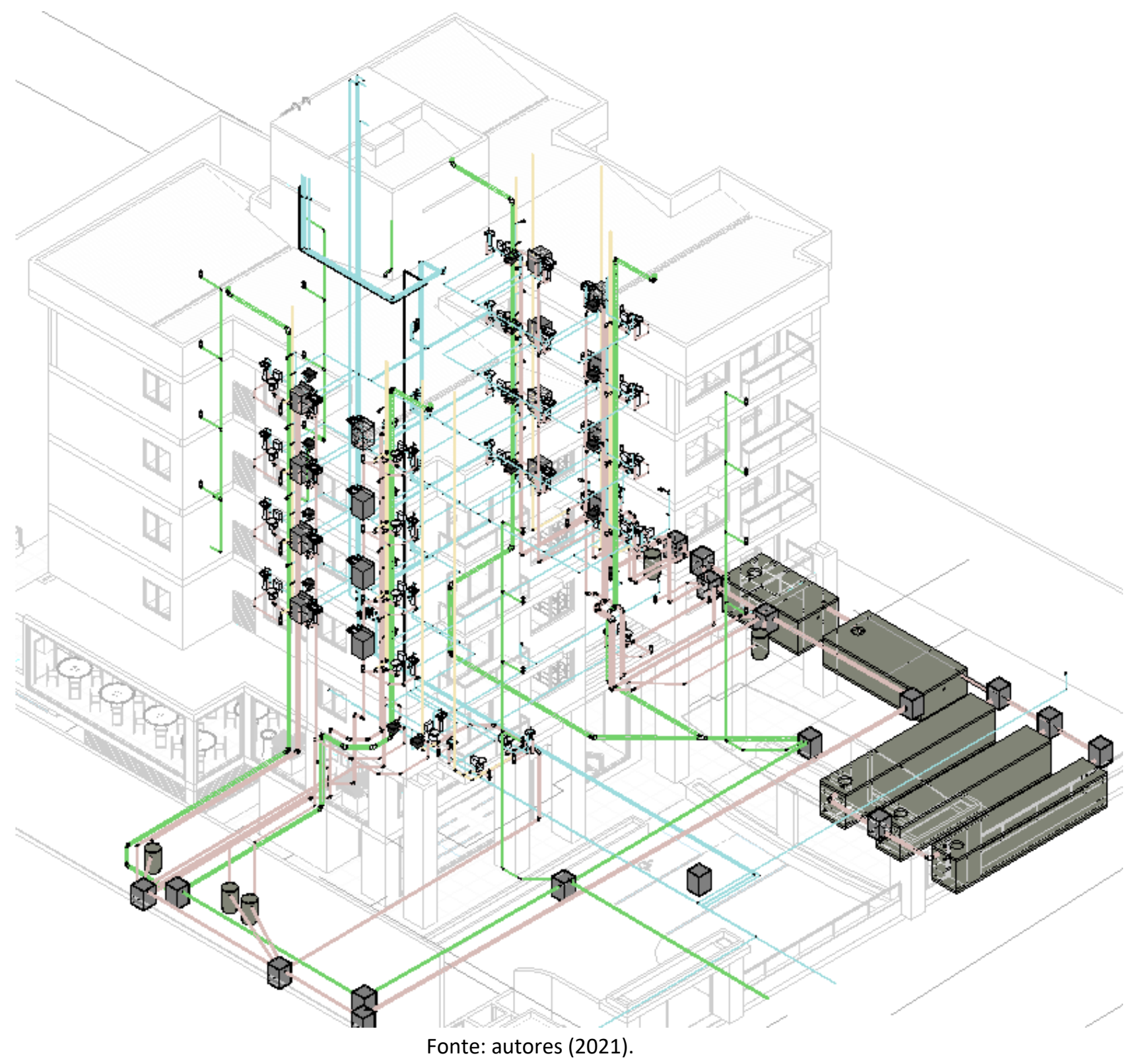

Ademais, consoante Catelani (2016, p.29), qualquer informação ou revisão realizada em qualquer parte do modelo é automaticamente propagada para as demais partes do projeto, facilitando a visualização da distribuição do sistema, conforme pode ser visto na Figura 5 em que tem-se a tubulação de água, esgoto e pluvial unidos em um único projeto. Dando espaço para prever erros e solucioná-los, tornando a instalação mais eficiente e econômica. Além de ficar mais fácil de visualizar algumas incompatibilidades estruturais, como a passagem de um encanamento em um elemento estrutural, possibilitando visualizar um desvio no encanamento, trazendo o projeto mais próximo da realidade de uma instalação. 
Figura 5 - Modelagem de um apartamento - Software REVIT MEP

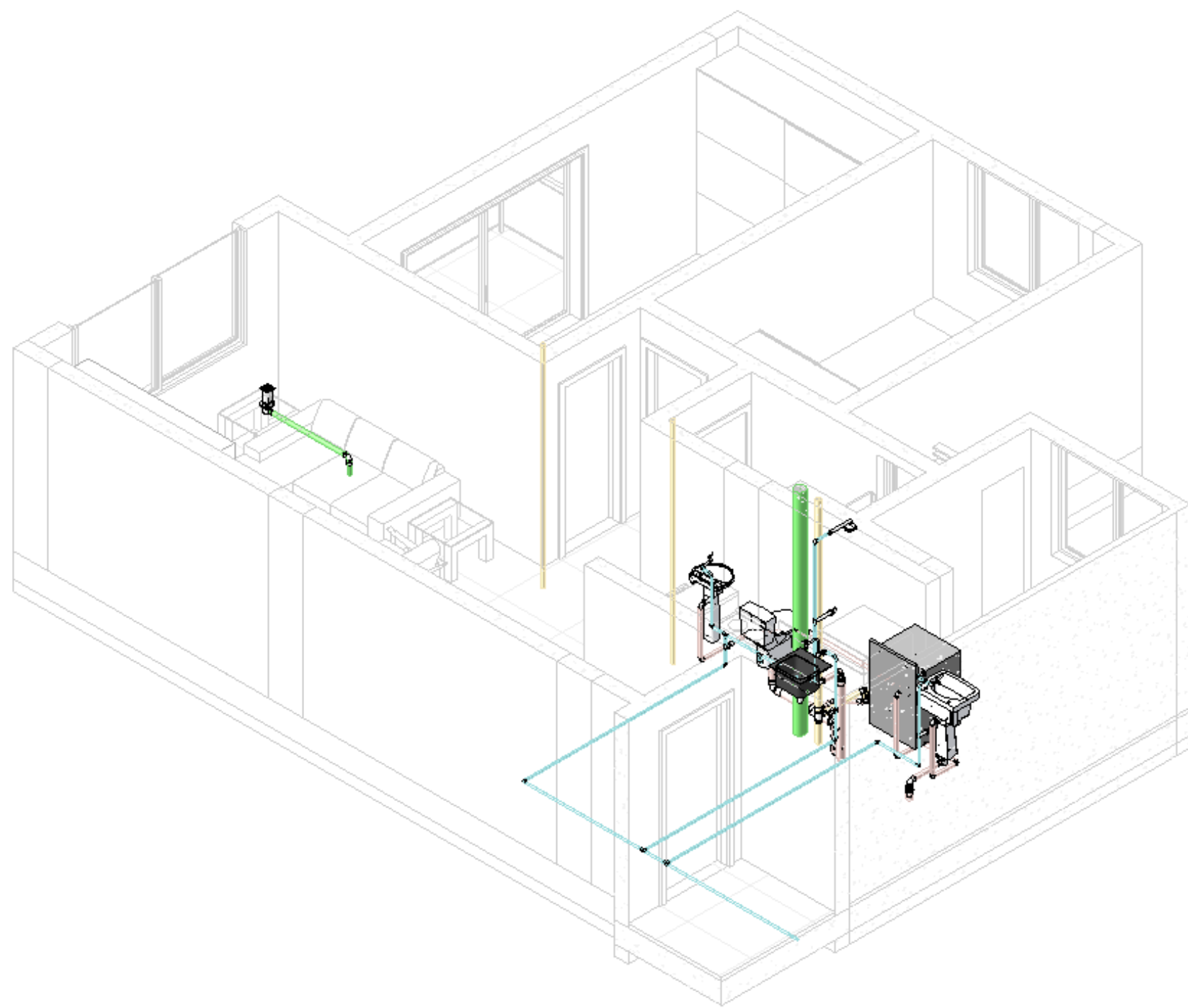

Fonte: autores (2021).

A grande dificuldade dos softwares de CAD 2D, é o processo de um desenho isométrico da tubulação. No REVIT, esta etapa do desenvolvimento do projeto é facilitada, visto que o modelo em 3D é gerado automaticamente. A Figura 6 ilustra o detalhamento isométrico das instalações de água fria e de esgoto sanitário de um banheiro. Nos projetos desenvolvidos em $C A D$, o detalhe das instalações de água fria é unifilar em perspectiva isométrica e o das instalações de esgoto é em planta baixa. Com o REVIT MEP, ambas instalações podem ser visualizadas juntas, se aproximando da sua construção real. 
Figura 6 - Modelagem Isométrica de um banheiro - Software REVIT MEP

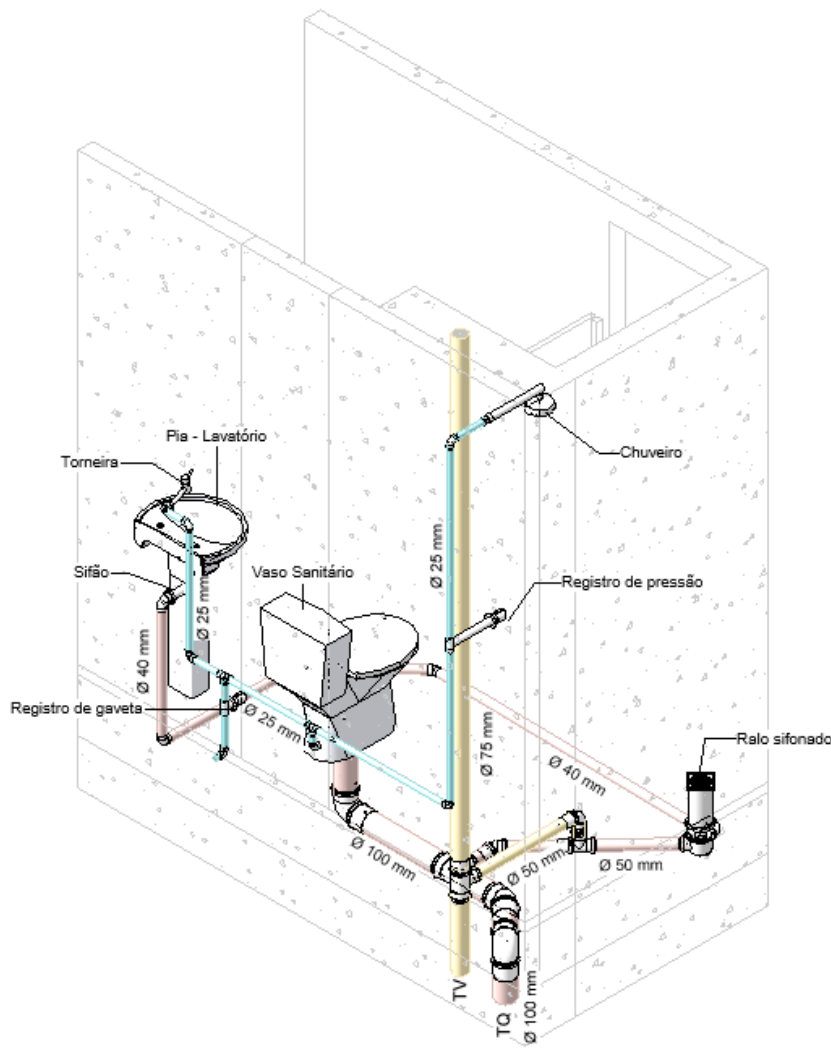

Fonte: autores (2021).

\section{CONSIDERAÇÕES FINAIS}

Conclui-se que enquanto ferramenta didática para compreensão das instalações hidrossanitárias, o software REVIT MEP mostrou-se efetivo. Ao desenvolver o projeto proposto na unidade curricular, os estudantes puderam visualizar praticamente todos os detalhes executivos do sistema, permitindo que compreendessem em detalhes a sua execução, garantindo eficiência à obra. Destaca-se a possibilidade de extração automática de quantitativos dos componentes paramétricos, como metragem das tubulações e quantidade de conexões, otimizando as etapas de orçamentação.

Acredita-se que o baixo interesse dos estudantes em aceitarem o desafio de desenvolver seus projetos em REVIT, ou seja, em conceito BIM, dá-se pelo desconhecimento dos detalhes do uso da ferramenta e, também, por possuírem computadores com baixo desempenho.

Além disso, observa-se que existe um crescente interesse do mercado em realizar projetos compatibilizados em BIM, ao acompanhar os estágios obrigatórios curriculares. Neste sentido, é enfatizado que a demanda por profissionais com domínio nesse software é essencial.

\section{REFERÊNCIAS}

BRASIL. Decreto no 10.306, de 2 de abril de 2020. Estabelece a utilização do Building Information Modelling na execução direta ou indireta de obras e serviços de engenharia realizada pelos órgãos e pelas entidades da administração pública federal, no âmbito da Estratégia Nacional de Disseminação 
do Building Information Modelling- Estratégia BIM BR, instituída pelo Decreto no 9.983, de 22 de agosto de 2019.. . Disponível em: https://www.in.gov.br/en/web/dou/-/decreto-n-10.306-de-2-deabril-de-2020-251068946 Acesso em: 10 jul. 2021.

CHUCK, E.; PAUL, T.; RAFAEL, S.; KATHLEEN, L. Manual de BIM: Um guia de modelagem da informação da construção para arquitetos, engenheiros, gerentes, construtores e incorporadores. Porto Alegre: Bookman, 2014. 9788582601181. Disponível em: https://app.minhabiblioteca.com.br/\#/books/9788582601181/ . Acesso em: 10 Jul 2021

INSTITUTO FEDERAL DE SANTA CATARINA (IFSC). Projeto Pedagógico de Curso - Engenharia Civil. Florianópolis, $2013 . \quad$ Disponível em: http://florianopolis.ifsc.edu.br/images/stories/ppc/graduacao/ppc\%20engenharia\%20civil.pdf Acesso em: 10 jul. 2021.

KENSEK, K. Building Information Modeling (BIM) - Fundamentos e Aplicações. Rio de Janeiro: Elsevier, 2018. 9788595153011. Disponível em: https://app.minhabiblioteca.com.br/\#/books/9788595153011/ Acesso em: 10 Jul 2021

CATELANI, Wilton Silva. Coletância implementação do BIM para construtoras e incorporadoras V.1: Fundamentos BIM. 1 Edição. Brasília, Distrito Federal: Editora Gadioli Cipolla Branding e Comunicação, 2016. 